\title{
Escola Digital Fortaleza: Uso de Objeto Digital de Aprendizagem na Perspectiva de Inovação das Práticas Pedagógicas
}

\author{
Selma Bessa Sales ${ }^{1}$, Wladia Queiroz Bessa Belém Moreira1, Marcos Dionisio Ribeiro \\ do Nascimento ${ }^{1}$, Renata Aquino Ribeiro \\ ${ }^{1}$ Secretaria Municipal da Educação (SME)/ Prefeitura Municipal de Fortaleza (PMF) \\ Fortaleza - CE - Brasil \\ ${ }^{2}$ E. I. Pesquisas \\ selmabessa0808@gmail.com, wqmoreira@gmail.com, raquino@gmail.com, \\ marcosdionisioegmail.com
}

\begin{abstract}
This work discuss the context of the Platform Fortaleza Digital School in the scenario of the continued formation and in service of the readapted teachers. Also, this work takes this conjuncture to analyze if there was the valorization and the use of digital technologies in the Education of Fortaleza/Ce. municipal schools since from the knowledge and access to the mentioned platform. With this in view, this work investigates who these teachers are, which is the profile of those teachers and if the knowledge learned in the training contributed to the development of innovative pedagogical practices from the use of digital learning objects (ODA). As a result of this analytical effort, it appears that the indicated platform provides a favorable environment for the process of qualified incorporation of digital technology into pedagogical planning, and demonstrated that there are still many challenges to be faced for the effective use of ODA in the classroom.
\end{abstract}

Resumo: O trabalho discute o contexto da Plataforma Escola Digital Fortaleza no cenário da formação continuada e em serviço dos professores readaptados. Ele toma essa conjuntura para analisar se a partir do conhecimento e acesso à referida plataforma houve a valorização e o uso das tecnologias digitais na educação nas escolas municipais de Fort/Ce. Com esse propósito, procura-se investigar aqui, quem são e qual é o perfil desses docentes ao mesmo tempo em que analisa se os saberes aprendidos na formação contribuíram para o desenvolvimento de práticas pedagógicas inovadoras a partir do uso de Objetos Digitais de Aprendizagem (ODAs). Resultante desse esforço analítico depreende-se que a plataforma indicada constitui um ambiente favorável ao processo de incorporação qualificada da tecnologia digital no planejamento pedagógico, e demonstrou por sua vez, que ainda são muitos os desafios a serem enfrentados para o efetivo uso de ODA na sala de aula.

\section{Introdução}

O avanço tecnológico vem favorecer o surgimento de diferentes conteúdos digitais bem como a construção e aplicação desses recursos, que o professor pode lançar mão para auxiliar sua ação docente na participação ativa do aluno no desenvolvimento da aprendizagem. 
Paralelo a essas perspectivas, foram surgindo também outras concepções de ensino e aprendizagem bem como diferentes possibilidades de construção, desenvolvimento e aplicação de conteúdos digitais.

Os dados do CGI.br divulgados em 2015, por exemplo, mostraram que 96\% dos professores da escola pública demonstram forte adesão a conteúdos digitais para planejar suas aulas e usá-los na prática pedagógica com destaque para o uso de: imagens, questões de avaliação, textos, vídeos, vídeo aulas, listas de leituras, apresentações temáticas, programas/software, jogos e outros.

Nesse panorama, a compreensão dos objetos de aprendizagem (OA) aqui mencionados como objetos digitais de aprendizagem (ODA) ${ }^{1}$ é de extrema importância para o desenvolvimento e compreensão desse estudo por se tratarem de recursos apresentados em diversos formatos de mídias como jogos, aulas em vídeo, áudio, simuladores, animações, aplicativos, softwares educativos, mapas e livros interativos, etc.

Apesar de possuírem muitas definições, todas partem do mesmo pressuposto de que os objetos digitais são elaborados para serem usados, prioritariamente, no ambiente escolar. Wiley (2000), em sua publicação sobre programação orientada a objetos, considera um OA como qualquer unidade/instrução digital ou não digital, que pode ser utilizada, reutilizada ou referenciada por tecnologias voltadas para o aprendizado.

Castro-Filho (2007) corrobora com essa ideia quando destaca que mesmo que não haja um consenso referente à definição para um objeto de aprendizagem, já existe uma manifestação positiva por parte de vários autores ao concordar que os mesmos devam ser digitais, acessados através do computador e preferencialmente, pela internet. Outro fator importante é que esses materiais não devem ser pesados, para que, assim, seja evitado o uso de muita memória, bem como, possam os mesmos, ser reutilizáveis e possuir um objetivo educacional específico, isto é, que sejam referenciados com algum conteúdo das disciplinas escolares foco da formação dos alunos.

Com a adoção das tecnologias digitais dentro e fora das salas de aula os ODAs favorecem o acesso fácil aos temas de estudo configurando-se em uma nova forma de atuação do professor frente a esses recursos, possibilitando ao sujeito engajar-se de forma independente e autônoma.

O presente trabalho trata, portanto de uma pesquisa descritiva de abordagem quali-quantitativa sobre o panorama da inserção da plataforma Escola Digital em Fortaleza/Ce, no contexto da Secretaria Municipal da Educação, a partir da concepção da customização com funcionalidades para personalização da identidade visual, da linguagem e recursos digitais selecionados de forma articulada com o currículo vigente.

Analisam-se depois, aspectos relevantes do curso na modalidade EaD "Tecnologia e Currículo", ofertado pela plataforma supracitada, para os professores de apoio pedagógico aos projetos de tecnologias educacionais desenvolvidos nas escolas.

E por último identificam-se as contribuições propiciadas pelo acesso ao amplo repositório de ODAs a fim de situar sua utilização enquanto possibilidade de integração na prática docente como fator de desenvolvimento e inovação pedagógica.

\section{Contexto sobre a Plataforma Escola Digital Fortaleza - Cenário de uso}

\footnotetext{
${ }^{1}$ Saiba mais sobre o que é um ODA, acessando "Currículo Mais" Nukácia Araújo em: $<$ https://www.youtube.com/watch?v=b1wwHpENGJs $>$ Acesso em: agosto de 2014
} 
No contexto atual podemos contar com inúmeros ambientes de compartilhamento e desenvolvimento de materiais didáticos na rede. Em 2016, objetivando-se implementar e disponibilizar a plataforma Escola Digital ${ }^{2}$ na Rede Municipal de Fortaleza com o oferecimento de recursos digitais e abertura de oportunidades para a produção e publicação de materiais por professores da rede, foi criada $^{3}$ a plataforma Escola Digital Fortaleza.

A concepção e o desenvolvimento da referida plataforma passou por dois momentos: o primeiro referente à customização visual e de conteúdos e o segundo referente à mobilização para uso.

Para deixar a plataforma mais atraente e amigável, foi feita a parte da implementação da customização, caracterizando assim, a identidade visual, etapa que já se encontra concluída. Definiam-se, portanto as características próprias como nome, domínio, imagem principal, cores, logomarca, menu de links, boxes de conteúdo criação de listas, filtros em destaque, etc., enquanto que a customização de conteúdos como curar novos ODAs disponíveis na internet, ainda encontra-se em andamento.

Relativos ao segundo momento do processo, foram realizadas ações concernentes à rede como coordenar, organizar, orientar e acompanhar o uso da plataforma na rede pública de educação; promover formação, orientando sobre seu uso e suas possibilidades pedagógicas; manter e atualizar a plataforma com novos recursos digitais e planejamentos de aulas.

Consideramos importante ressaltar o acompanhamento dado pela Rede de Liderança (Escola Digital) que realiza dois encontros presenciais ao ano, e Hangouts ${ }^{4}$ mensais com os estados e municípios para construção de estratégias de ação coletiva no propósito de consolidar a plataforma para o professor da rede escola digital.

Com essas ações, concebeu-se que o ambiente fosse para o compartilhamento de novos saberes, práticas e metodologias por técnicos, coordenadores, professores e alunos e que os mesmos o utilizassem de forma a aprimorar a experiência dentro e fora da sala de aula.

A Figura 1 diz respeito à identidade visual da plataforma após customização. Em sua página inicial constam os ícones de navegação (Ajuda, Professores, Gestores Escolares, Alunos, Secretaria, Colabore e Contato) e a opção de acesso para o usuário mediante cadastro com login e senha.

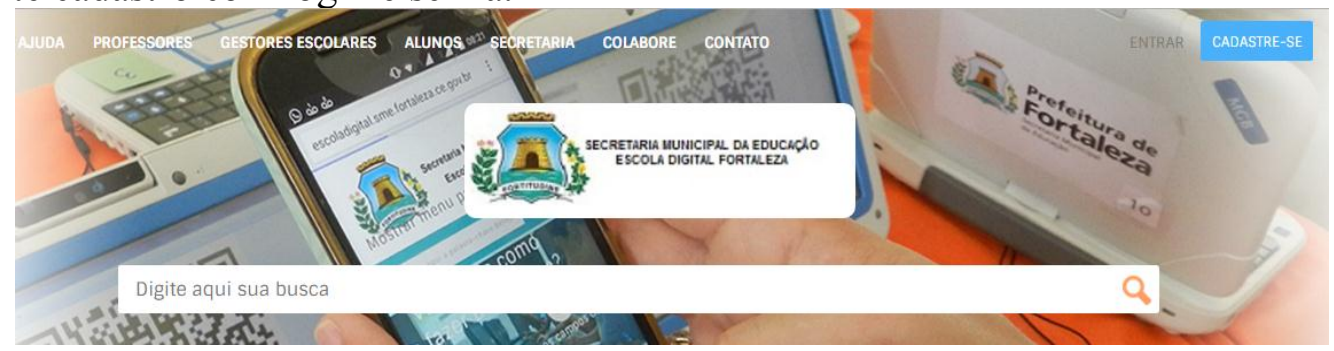

Figura 1- Tela inicial da plataforma Escola Digital Fortaleza

\footnotetext{
${ }^{2}$ Projeto Escola Digital lançado em 2013 é uma plataforma gratuita de busca de recursos digitais de aprendizagem.

${ }^{3}$ Informações sobre o Termo de Cooperação - Instituto Natura, Instituto Inspirare, Fundação Telefônica e Prefeitura Municipal de Fortaleza - Disponível em <https://goo.gl/52rOn6> Acesso em: novembro 2016.
${ }^{4}$ Hangout
"Customização
da
Plataforma".
Disponível
em:

$<$ https://www.youtube.com/watch? $\mathrm{v}=\mathrm{j} 8 \mathrm{tVjNz} 3 \mathrm{kHs}>$ Acesso em: março de 2017.
} 
Ainda na página inicial é possível visualizar o ícone "Explore" (apresenta os ODAs por etapas do ensino, ano modalidade, disciplina tipo de mídia); "Apoio ao Professor" (Materiais pedagógicos, Curso Tecnologia na Educação), "Colabore" (Crie um Plano de Aula e um ODA), "Listas" e "Como Começar", com informações detalhadas acerca do potencial desse material.

A plataforma possui uma navegabilidade dinâmica e prática inserida em um sistema de busca que permite ao professor filtrar as informações e personalizar o seu uso.

Segundo Hoyos (2013, p.122-137), conforme citado por Souza et all (2015, p. 530), a utilização das TIC na educação tem sido fortemente fomentada durante a última década com a adaptação generalizada dos AVAs que cada vez mais se destacam nesse cenário por proporcionarem um espaço de trabalho personalizado, podendo o docente projetar e instanciar atividades de aprendizagens individuais e colaborativas.

O portal também disponibiliza informações sobre o nível de acessibilidade para pessoas com deficiência e indica recursos digitais que podem ajudar na criação de novos objetos digitais de aprendizagem, trabalhos com temas transversais e realização de projetos na comunidade, entre outras possibilidades educativas.

Dessa forma, o ambiente plataforma Escola Digital Fortaleza configura-se como um suporte às práticas pedagógicas e pode promover a aprendizagem significativa por apresentar os atributos que estimulam a navegação segundo Dorfmann (2003), como: Conveniência; Confiabilidade; Acessibilidade; Atualização; Variedade de Serviços; Personalização, Interatividade; Navegação; Conteúdo; Design, podendo ser utilizado a partir das necessidades sentidas por docentes da rede pública de ensino.

A referida plataforma é gratuita, aberta, para busca de objetos digitais de aprendizagem em todas as etapas da Educação Básica. Ela também congrega diversos recursos e conteúdos da internet tais como, games, vídeos, infográficos, mapas, animações e simuladores que podem ser utilizados por quem deseja aprender e ensinar utilizando a tecnologia digital. Atualmente são $6470 \mathrm{ODAs}^{5}$ cadastrados, organizados segundo os PCNs (Parâmetros Curriculares Nacionais), sendo a busca realizada por filtros, por disciplina, ano, tipo de mídia e outros.

\section{Expectativas e vivências de professores em formação EaD}

Para que o professor da Rede Municipal de Ensino de Fortaleza possa usar os recursos da plataforma em sua prática pedagógica é necessária uma formação adequada que implica, não apenas em dominar a tecnologia e suas inúmeras possibilidades, mas que também instigue o professor a refletir, com profundidade, sobre o seu papel na comunidade educacional e na sociedade da informação.

No menu "Apoio ao Professor" que fica na página inicial, encontra-se o curso denominado "Tecnologia e Currículo" que está disponível gratuitamente para professores e gestores.

O objetivo do curso é propiciar o estudo e a reflexão sobre as relações entre a tecnologia e a educação a partir da exploração do repositório de objetos digitais de aprendizagem, a fim de favorecer o desenvolvimento de práticas educativas inovadoras, visando à aprendizagem dos alunos bem como garantir a abertura de oportunidades para a produção e publicação de materiais por professores da rede.

${ }^{5}$ Fonte: Material cedido gentilmente por Escola Digital. Disponível em: <http://www.escoladigital.org.br/> Acesso em: Julho 2016. 
Segunda Almeida (2003, p.327-340), conforme citado por Ferro et all (2011, p. 2), os ambientes virtuais de aprendizagem (AVA) são ambientes computacionais com a finalidade de integrar diversas mídias e dar suporte, inclusive on-line para a educação à distância. Dessa forma, ao escolher uma plataforma de ensino à distância, é importante atentar para as possibilidades de personalização que ela oferece: logos, cores, estrutura de conteúdos, domínios, certificados, funcionalidades, entre outros. E a plataforma Escola Digital Fortaleza ${ }^{6}$ é um exemplo de plataforma que atende a todas essas especificações.

Vale destacar que o curso EaD percorre as temáticas relativas aos impactos da cultura digital na sociedade contemporânea e na escola, a integração das TDICs no currículo, os objetos digitais de aprendizagem e o uso contextualizado desses recursos no planejamento pedagógico.

O curso vem organizado com os seguintes módulos: Currículo e Tecnologia; plataforma Escola Digital Fortaleza; Curando e produzindo ODAs; Planejando com o uso de ODAs e ferramentas.

O mesmo oferece certificação progressiva com diferentes níveis de aproveitamento (20h/a ou 40h/a) validado pelo MEC e apresenta atividades dinâmicas que envolvem análises de vídeos, fóruns, criação de podcast, revista digital etc. com avaliação contínua. É de forma flexível, com autonomia na gestão do tempo com duração de dois meses aproximadamente.

Partindo da perspectiva de que todos os professores poderiam fazer a formação em $\mathrm{EaD}$, naquele momento, vislumbramos atender prioritariamente os professores que aderiram $^{7}$ à função de apoio pedagógico aos projetos de tecnologias educacionais uma vez que hoje as escolas do Sistema Público Municipal de Ensino de Fortaleza podem contar com atuação deles nos Laboratórios de Informática Educativa (LIE).

Considerando a qualificação desse profissional para o trabalho pedagógico com as tecnologias e na descoberta de novas habilidades e potencialidades para um novo sentido ao seu fazer pedagógico, (Sales, Nascimento, Rodrigues, 2016 p.757), o Núcleo de Tecnologia Educacional -NTE/Fortaleza/Ce, em parceria com a Escola Digital, iniciou em novembro de 2016 o curso EaD da plataforma Escola Digital Fortaleza ${ }^{8}$.

Esse projeto piloto teve como objetivo conquistar a adesão à proposta de utilização da plataforma Escola Digital Fortaleza e serviu como uma estratégia para despertar o interesse quanto ao uso dos objetos digitais de aprendizagem na sala de aula para o desenvolvimento de novas práticas pedagógicas.

Assim, nossa pesquisa sistematiza a participação desses docentes durante a realização do curso com dados coletados a partir de dois instrumentos: Diagnóstico inicial sobre perfil e atuação profissional dos cursistas - (Formulário Google Drive) ${ }^{9}$ e diagnostico final sobre a participação no curso EaD e uso de ODA na prática docente. (Formulário Survey) ${ }^{10}$.

\footnotetext{
${ }^{6}$ Disponível em <http://escoladigital.sme.fortaleza.ce.gov.br> Acesso Agosto 2016.

${ }^{7}$ Maiores informações sobre o Processo de Adesão: Professor em Readaptação de Função: basta acessar $<$ https://goo.gl/0ynJZN $>$ Acesso dezembro 2015.

${ }^{8}$ Disponível em <http://escoladigital.sme.fortaleza.ce.gov.br/ead_rede/> Acesso Novembro 2016.

9 Diagnóstico Inicial- EAD Escola Digital Fortaleza - Google Drive- Disponível em $<$ https://goo.gl/kE42Tq> Acesso Março 2017

${ }^{10}$ Pesquisa Survey Curso EaD - "Tecnologia e Currículo" Disponível em $<$ https://pt.surveymonkey.com/r/87WDCNL> Acesso Março 2017
} 
De um universo de oitenta e nove professores, vinte e quatro responderam os formulários, sendo que, até a presente data os demais cursistas continuam participando do curso. A análise dos dados foi realizada por meio de estatística descritiva.

A seguir, a análise das respostas relevantes:

Tabela 1 - Quadro demonstrativo das respostas

\begin{tabular}{|c|c|}
\hline \multirow{3}{*}{$\begin{array}{c}\text { Sobre a atuação e } \\
\text { formação } \\
\text { profissional dos docentes }\end{array}$} & - $62.5 \%$ apresentam idade acima de 45 anos; \\
\hline & - $\mathbf{8 7 . 5} \%$ dos docentes tem mais de 10 anos de profissão; \\
\hline & - $\mathbf{3 7 . 5 \%}$ já participaram entre 1 a 2 vezes de cursos online; \\
\hline \multirow{3}{*}{$\begin{array}{c}\text { Sobre acesso e } \\
\text { participação no curso } \\
\text { EAD }\end{array}$} & - 43,48\% já finalizaram o curso; \\
\hline & $\begin{array}{l}\text { - } \mathbf{1 7 , 3 9 \%} \text { se encontram respectivamente nos Módulo } 1 \text { Currículo e } \\
\text { Tecnologia e Módulo } 4 \text { - Planejando com o uso de ODAs e ferramentas }\end{array}$ \\
\hline & $\begin{array}{l}\text { - } \mathbf{4 1 , 6 7 \%} \text { indicaram como atividade mais interessante a criação da } \\
\text { revista digital Scoop.it. }\end{array}$ \\
\hline \multirow{3}{*}{$\begin{array}{l}\text { Sobre o uso do ODA } \\
\text { na prática docente }\end{array}$} & $\begin{array}{l}\text { - 58,33\% - Utilizaram um Objeto Digital de Aprendizagem (ODA) em } \\
\text { alguma atividade pedagógica. }\end{array}$ \\
\hline & $\begin{array}{l}\text { - 95,65\% - Consideram que o curso colaborou com sua própria } \\
\text { formação e dará suporte para sua futura prática. }\end{array}$ \\
\hline & $\begin{array}{l}\mathbf{- 9 5 , 8 3 \%} \text { Recomendariam o curso para algum outro professor, } \\
\text { coordenador ou gestor. }\end{array}$ \\
\hline
\end{tabular}

A análise do perfil dos participantes do curso EaD leva à compreensão inicial de que, 15 deles apresentam idade superior a 45 anos. Esse aspecto é interessante por considerar que o sujeito já se encontra imerso no mundo do trabalho. Além disso, aponta que 21 desses docentes apresentam mais de 10 anos de profissão e que ao longo desse tempo estiveram trazendo conhecimento e experiência no exercício da prática docente. $\mathrm{E}$ agregado às formações, 9 deles já haviam participado entre 1 a 2 vezes de cursos on line, aspectos esses relevantes que definem o aprimoramento do desenvolvimento profissional desses sujeitos.

Sobre acesso e participação no curso EaD "Tecnologia e Currículo", a pesquisa revelou que 10 professores já finalizaram o curso, e 4 se encontram respectivamente no Módulo 1 Currículo e Tecnologia e Módulo 4 - Planejando com o uso de ODAs e ferramentas.

Destaca-se também que 22 professores foram unânimes ao considerar que o curso colaborou com a própria formação e que o mesmo dará suporte para sua futura prática pedagógica. Há nos resultados 23 professores que recomendariam o curso para outros profissionais da educação como coordenadores e gestores.

No destaque dado pelos professores em formação quanto às tarefas mais interessantes, percebe-se que os mesmos se apropriaram de novas ferramentas digitais, aumentaram a autoestima e autoconfiança bem como a produção de recursos digitais, e 
que 10 deles criaram a revista digital Scoop.it ${ }^{11}$. O curso on-line trouxe um desafio, a possibilidade de capacitar o professor e de compartilhar suas produções colaborativamente.

Mesmo com vivência anterior em cursos $\mathrm{EaD}$, apresentando conhecimento sobre o que é um ODA, 16 deles ainda não tinham participado com autoria de algum ODA no espaço "Colabore"12. Essa era também mais uma estratégia de mobilização e incentivo para professores colaborarem para a construção do acervo, indicando os ODAs de sua autoria.

Outro aspecto que merece ser evidenciado é sobre os saberes prévios do professor. A pesquisa revelou que 14 docentes já conheciam um ODA e que já os utilizam em atividades pedagógicas.

No caso específico do grupo dos professores de apoio pedagógico aos projetos de tecnologias educacionais em que a pesquisa foi realizada, esses números mostram o desejo do docente de aprimoramento profissional, a disposição em participar de processos de formação continuada e o grau de satisfação com a plataforma Escola Digital Fortaleza. Como podemos constatar nas afirmações:

A Escola Digital Fortaleza nos proporciona, enquanto educadores, um grande apoio, tendo em vista que temos um acervo bem considerável de materiais pedagógicos digitais, subsidiando o processo de ensino e aprendizagem realizado em sala de aula. Traz ainda a possibilidade de capacitar o professor através do curso on-line e de compartilhar suas produções colaborativamente. (Professora de apoio pedagógico aos projetos de tecnologias educacionais, 2016).

Com a pesquisa realizada identificou-se que o professor tem buscado elementos de apoio em seus planos pedagógicos e os ODAs podem, em muito contribuir nesse processo por apresentarem-se como meio de apoio as aulas presenciais ou à distância.

Com isso, o docente passa a contar com recursos digitais que podem auxiliá-lo em seus planos pedagógicos para um melhor aproveitamento do conteúdo estudado pelo aluno.

Algumas barreiras foram apontadas também ao longo do caminho: a pouca estrutura de funcionamento de internet oferecida no LIE; professores cursistas que não possuíam acesso ao curso em casa; necessidade de apropriação da plataforma para realização das atividades; ajustes na própria plataforma, dentre outras.

Entretanto, a partir do elencado até aqui, constata-se que é preciso estimular os professores a planejar suas aulas explorando todas as ferramentas que a plataforma digital oferece. É sempre bom lembrar que é fundamental a qualificação do professor, ou seja, é a atitude dele, seu preparo e criatividade que vão fazer toda a diferença.

\section{Integração da plataforma Escola Digital Fortaleza à prática docente}

No decorrer da formação com a busca de incorporá-la no planejamento das aulas para o desenvolvimento curricular foram surgindo novas reflexões sobre os limites e possibilidades dos ODAs no processo ensino aprendizagem.

\footnotetext{
${ }^{11}$ Veja exemplo de Revista Digital produzida pelos cursistas acessando o link $<$ http://www.scoop.it/t/matematicaparacriancas> Acesso em: Novembro 2016.

${ }^{12}$ Colabore "Sugira um ODA" - Disponível em: <http://escoladigital.sme.fortaleza.ce.gov.br/colabore> Acesso em: Agosto 2016
} 
A exemplo disso, para análise desse estudo, a pesquisa acompanhou uma ação desenvolvida, utilizando um ODA na sala de aula por uma professora regente e uma professora em readaptação de função numa unidade escolar. Considerando a qualificação da professora readaptada para o trabalho pedagógico com a tecnologia e a condição favorável do LIE que conta com internet e equipamentos funcionando, foi possível desenvolver a atividade que trouxe descobertas de novas habilidades e potencialidades para um novo sentido ao fazer pedagógico.

A partir do envolvimento da professora de apoio pedagógico aos projetos de tecnologias educacionais no curso EaD "Tecnologia e Currículo" da plataforma Escola Digital Fortaleza, a atividade foi desenvolvida para apoiar estudos realizados em sala de aula com o objetivo de aprimorar a prática do processo de aquisição da leitura e escrita dos estudantes.

E concordando com as ideias de Ribeiro et all. (2016 p. 57), sobre a aprendizagem enquanto processo existente para a construção de conhecimento dos alunos, e a necessidade de transformá-los em autores a partir de experiências coletivas, a professora de apoio às tecnologias reuniu esses elementos após a formação da qual participou para a busca do ODA na plataforma Escola Digital Fortaleza seguindo a questão: qual ODA selecionar de acordo com o conteúdo explorado em sala de aula especialmente em atividades de alfabetização e letramento?

De acordo com o planejamento didático foi realizada a seleção do jogo educativo Palavras e Desenhos ${ }^{13}$, disponível no site Escola Games, por ter associação de desenhos e palavras em português. Tanto para estimular a capacidade de estabelecer relações entre figuras e palavras, como para o aperfeiçoamento da coordenação motora.

Esse ODA está inserido no tema curricular Prática de Leitura e foi selecionado para o aprimoramento das práticas e intervenções de leitura realizadas no processo escolar de alunos do $1^{\mathrm{o}}$ ano, estando entre os níveis silábico e silábico alfabético, bem como alternativa lúdica para enriquecer o processo de alfabetização.

Quanto à dinâmica utilizada a atividade se dá da seguinte forma: após a atividade em aula os alunos utilizam o LIE como apoio aos estudos realizados em sala, com o objetivo de aprimorar o desenvolvimento dos processos de aquisição de leitura e escrita do grupo.

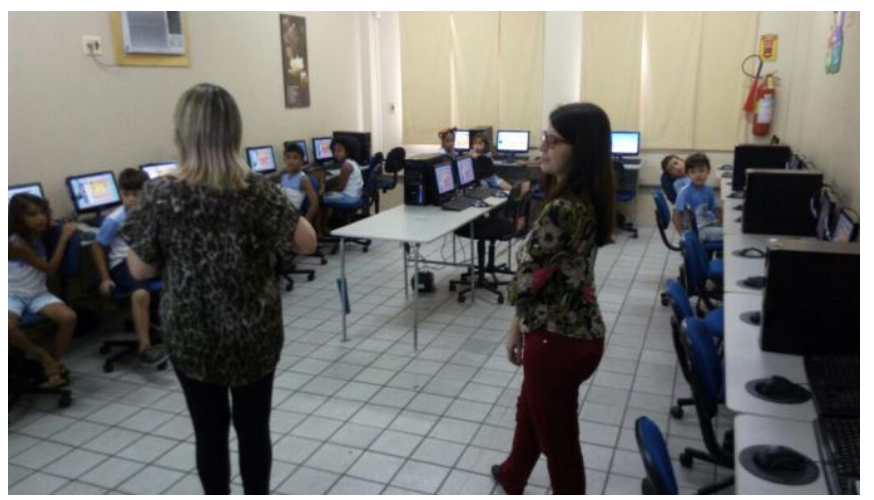

Figura 2: Alunos utilizando o ODA com as professoras.

Nesse momento os alunos tiveram contato com o objeto digital de aprendizagem o jogo "Palavras e Desenhos". No decorrer da aula planejada previamente em conjunto com $\mathrm{o}$ professor de apoio às tecnologias, com efeito, percebe-se que a parceria entre a

\footnotetext{
${ }^{13} \mathrm{http}: / /$ www.escolagames.com.br/jogos/desenhosPalavras/
} 
professora regente e a professora de apoio pedagógico aos projetos de tecnologias educacionais estava presente. Essa parceria é essencial para que exista uma adequação entre os conteúdos trabalhados em sala de aula e os abordados no LIE.

No que diz respeito à apropriação e uso do referido ODA pela professora regente é importante destacar que houve um favorecimento do gerenciamento da aprendizagem, bem como um melhor aproveitamento do tempo (Castro-Filho, 2006).

\section{Resultados}

Os dados recolhidos revelam que o fato de poder contar com uma plataforma personalizada contendo cerca de mais de seis mil ODAs em vários formatos de mídias digitais, disponíveis de forma online e off line, favorece os docentes utilizarem esse espaço de formação e colaboração para auxiliar no planejamento das aulas, criar listas de ODAs com indicação para grupos de alunos, criar ODAs, discutir nos fóruns sobre tecnologia e currículo, desenvolvendo assim ações inovadoras para ensinar e aprender no âmbito do uso das tecnologias na educação.

Com base no acompanhamento e desenvolvimento da aula constatou-se que os professores envolvidos reconhecem a importância da utilização do ODA "Palavras e Desenhos' ressignificando assim, as formas tradicionais de aprender na alfabetização. A utilização desse recurso no processo de ensino aprendizagem dos alunos auxiliou, de forma simples, a fixar os conteúdos, dinamizar a aula, o aluno experimentou, verificou e associou a palavra à imagem ampliando dessa forma seus saberes.

Conclui-se a partir dos resultados obtidos que a formação atingiu seu objetivo de auxiliar os educadores a desenvolver e inovar as estratégias de ensino-aprendizagem, tornando-se gestores do conhecimento, gerando novas formas de ensinar e aprender para a melhoria da autoestima dos sujeitos resultando em mudança em sua ação e postura docente.

\section{Considerações Finais}

Pretendeu-se, com esta reflexão, fomentar a discussão sobre a importância da inserção de tecnologia no ambiente escolar, tanto para promoção de novas dinâmicas em sala de aula como para o surgimento de novos perfis a serem desempenhados pelos professores em readaptação de função, desde que os mesmos estejam dispostos a ensinar, incentivar e propor atividades que aprimoram, enriquecem a aprendizagem e consolidam a parceria com o professor regente.

Atualmente, a plataforma Escola Digital Fortaleza vem sendo utilizada pelos professores que participam do projeto piloto. É importante também evidenciar que, para que os benefícios com o uso da plataforma Escola Digital Fortaleza ocorram, a mesma deve ser adotada por todo o sistema de ensino local. No caso de Fortaleza, o governo municipal já desenvolve ações de infraestrutura tecnológica apropriada nas escolas e estratégias de formações para que a plataforma não fique a cargo de algumas escolas e a formação em $\mathrm{EaD}$ somente para um grupo de professores.

Com a disponibilização da plataforma na rede municipal, os ODAs tornam-se acessíveis a um número bem mais significativo de usuários, com a possibilidade de serem encontrados e reusados. Diante disso teremos dados suficientes para analisar o verdadeiro resultado do impacto na aprendizagem dos alunos através dessa estratégia, sendo uma necessidade para um trabalho futuro. 
VI Congresso Brasileiro de Informática na Educação (CBIE 2017)

Anais do XXIII Workshop de Informática na Escola (WIE 2017)

Acreditamos no potencial desta plataforma e pensamos que há, ainda, um longo caminho a ser construído para que o acesso à internet torne-se adequado, haja vista que esse entrave impossibilita a utilização qualitativa desse repositório e de outros instrumentos por professores e alunos. A inovação ocorre quando ela passa a ser usada para promover e ampliar o aprendizado, como parte do processo.

\section{Bibliografia}

Castro-Filho, J. A. (2007) "Objetos de Aprendizagem e sua Utilização no Ensino de Matemática", IX Encontro Nacional de Educação Matemática, Belo Horizonte, MG. p. 2 Disponível em: $<$ http://paginapessoal.utfpr.edu.br/kalinke/novas-tecnologias/gruposde-pesquisa/pde/pdf/objetos_de_aprendizagem_e_EM.pdf $>$ Acesso em: julho de 2016.

POR QUE USAR UM ODA, 26/11/2016 - Disponível $<$ http://slideplayer.com.br/slide/350698> Acesso janeiro de 2017.

Coelho, A.S; Ribeiro, R.A; Mandaji, M.dos Santos; Costa, V.do Vale: Aprendizagem colaborativa: blogs, wikis e redes sociais no cotidiano da educação - Da Internet para a Sala de Aula - educação, tecnologia e comunicação no Brasil Jundiaí - São Paulo, 2016 pág. 57

Currículo Mais. Entrevista com Nukácia Araújo. 2'50'. Disponível em: $<$ https://www.youtube.com/watch?v=b1wwHpENGJs > Acesso em: agosto de 2014

Dormann, P. F. Atributos favoráveis à motivação para visitação de um site: estudo de um portal educacional. 2003. 93 f. Dissertação (Mestrado em Administração) - Escola de Administração, PPGO, UFRGS, Porto Alegre, 2003.

Encontros à distância- Março -Rede Escola Digital- Direção Sarah Faleiros - 1'53', Disponível em: <https://www.youtube.com/watch? $\mathrm{v}=\mathrm{j} 8 \mathrm{tVjNz} 3 \mathrm{kHs}>$ Acesso em: março de 2017

Ferro, M. R. da C.; Nascimento Jr., H. M.; Paraguaçu, F.; Costa, E. de B; Monteiro, L. A. L. Um modelo de sistema de recomendação de materiais didáticos para ambientes virtuais de aprendizagem. Anais do XVII WIE, Aracaju. 2011. Disponível em: <ttp://www.br-ie.org/pub/index.php/sbie/article/view/1643/1408> Acesso em: abril de 2017.

Souza T. I. A, Nunes A. O., Vasconcelos F. H. L., Andriola W. B., Mota J. C. M. 1, Almeida A. L. F. (2015). Aplicação de Técnicas de Exploração de Dados como Apoio a Avaliação de Atividades Desenvolvidas em um Ambiente Virtual de Aprendizagem (AVA) - p. 530. Anais dos Workshops do IV Congresso Brasileiro de Informática na Educação (CBIE 2015), Disponível em <http://brie.org/pub/index.php/wcbie/article/view/6054/4242> Acesso em: janeiro de 2016.

Pesquisa sobre o uso das tecnologias de informação e comunicação nas escolas brasileiras: TIC educação 2015 [livro eletrônico] = Survey on the use of information and communication technologies in brazilian schools: ICT in education 2015 / São Paulo: Comitê Gestor da Internet no Brasil - CGI.br 2016. p. 50. Disponível em: <http://cetic.br/media/docs/publicacoes/2/TIC_Edu_2015_LIVRO_ELETRONIC O.pdf $>$ Acesso em: julho de 2016.

Wiley, D.A. Connecting learning objects to instructional design theory: A definition, a metaphor, and a taxonomy. In D. A. Wiley (Ed.), The Instructional Use of Learning Objects (2000). Versão online: <http://reusability.org/read/chapters/wiley.doc $>, 15$ de Fevereiro de 2006. 